\title{
Can elevated pedestrian walkways be sustainable?
}

\author{
J. Rotmeyer \\ The University of Hong Kong, Hong Kong, People's Republic of China
}

\begin{abstract}
In most North American cities, taking pedestrians away from the street level potentially kills the street life. Raised walkways perform as lines connecting otherwise disconnected urban islands together, but fail quickly where pedestrian density is not high enough to sustain both levels. The networked connectivity acts not only as a public space linking together the built environment, but also distances pedestrians from vehicular pollution while redistributing the density of the ground layer. This paper looks specifically at how Hong Kong is able to sustain such a unique phenomenon facilitating permeability accentuated through a network of elevated walkways when most North American cities fail to function successfully for various reasons. It concludes by demonstrating how elevated walkways have been utilized for years; yet still project a visionary idea for future sustainable urban design.
\end{abstract}

Keywords: sustainability, elevated pedestrian walkway, urban layering, pedestrian movement.

\section{Introduction}

Sustainability is a concept developed to maintain social, economic, and environmental needs both now and in the future, to preserve for infinite generations. Hong Kong and several North American cities developed elevated walkway networks integrating human activity with the built environment. While the driving force behind Hong Kong's pedestrian walkways was efficiency and overcrowding, in Minneapolis and Calgary it was the extreme cold climate. Elevated networks add a sense of security and comfort, allowing a continuous flow of movement without interruption from vehicular traffic, stop lights and pollution. Pedestrian density is high enough in Hong Kong to support 
multiple layers of parallel pedestrian movement directly associated with economic activities. However, many North American cities often do not maintain enough pedestrian movement to facilitate the street level alone. There is a substantial difference evident between car dependent movement, and public transport. In Hong Kong $98 \%$ of the population rely on public transportation, becoming pedestrians at some point during their journey [1]. In cities like Minneapolis and Calgary, a high percentage of the population rely on private vehicles. This limits the number of pedestrians moving through downtown. High density may benefit both social and economical development, however environmental issues of overcrowding and pollution are concerns. Hong Kong embodies many of the necessary elements to maintain a sustainable elevated system. However, failing to provide community and multiple functions within the pedestrian network hinders the overall success.

With conflicting outcomes, a clear understanding is needed to determine if elevated walkways can be sustainable. For an elevated pedestrian network to succeed, it needs to be fully sustainable on all accounts, socially, economically and environmentally. The addition of elevated walkways is a direct response to different problems in North America and Hong Kong. An investigation is necessary to determine which one is more sustainable. The ultimate goal is to create a safe, comfortable, well-connected quality of life above the ground layer, without killing the street. To begin, a brief history of elevated walkways identifies what indicators can be drawn to determine a basic measure of sustainability. The next sections break down each indicator, comparing several US cities to Hong Kong, discussing how each contribute to form sustainable elevated walkway systems.

\section{Historical background}

Elevated walkways are not a new concept. Such innovative ideas began much earlier where dreams and imagination could exist as reality. Movies such as 'Metropolis' in 1927, and 'Things That Come' in 1936, envisioned a modern utopia with bridges spanning between buildings, giving their audience a city of the future [2]. These imaginary ideas led to visionary projects, each addressing various social, economic, and environmental issues. The following are early examples of elevated walkways, identifying a small piece of the puzzle to establish a starting point.

Le Corbusier envisioned optimal organization in his Voisin Plan (1925) creating what he believed was a better quality of life, separating pedestrians from vehicular movement. With an emphasis on private vehicular transportation, a continuous flow of movement allowed multiple tasks to function smoothly on multiple levels. This dynamic plan elevated people into the sky, creating a social constraint that pushed spatial boundaries and created an extreme separation of urban tolerance. The vast open spaces killed the streets below, and resulted as empty lost space. Surprisingly, North America has developed a similar urban form, by placing high emphasis on private vehicular transportation, allowing vast empty abandoned lots, and decayed downtown cores. 
Peter Cook of Archigram addressed both the spatial environment as well as the social impact with his "Plug-in City" [3]. This organized kit of parts, minus actual buildings, linked urban movement together vertically, horizontally and diagonally as a network of entangled modern utopia. It was an extreme example of a "lattice city structure" [4] that pushed movement too far. Instead of creating an organized flow of movement, the outcome was a tangled mess overemphasising connectivity, thus lacking a balance of open space. Entangled disarray, implementing a lack of open space, challenge most high dense urban environments today. Both Le Corbusier and Cook have taught us valuable lessons socially, economically and environmentally, by ultimately decaying the ground plane, limiting urban quality of life, and overplaying urban movement.

A multi-layered city can be sustainable if each layer maintains itself within a balanced functional network of movement and activity. For the purposes of this paper, the measure of sustainability will be discussed according to the social, economic, and environmental strengths prevalent to Hong Kong and the US. The goal is to determine a balanced ideal, which could ultimately support a fully sustainable elevated pedestrian network. The indicators for social and economic sustainability include private versus public, continuous flow, and ground floor decay. The environmental indicators addressed as quality of life, include high density and temperature control.

\section{Practical models}

While the previous ideas were mainly theoretical, North America exhibits a practical model, which has also been replicated in Hong Kong. Minneapolis and Calgary, two North American cities, developed extensive elevated pedestrian networks over the past 40 years. In the 1960 s, both cities embarked on such an urban phenomenon due primarily to extreme temperatures. Minneapolis developed its enclosed elevated network 10 years after the success of Green's South Dale Shopping Centre in 1952. A total of 28 bridges with a population of only 370,951 as of a 1980 census united the downtown core. Today, a total of 77 bridges spanning 8 miles interconnect the entire downtown on the second floor [5]. Calgary also developed a 9-mile system publicly owned by 1972. These inner city elevated networks challenged suburban malls bringing people back downtown [5]. By creating climatically controlled continuous spaces, they hoped to improve the overall economic potential of the downtown core.

Hong Kong on the other hand, responded to overcrowding and urban chaos, adding elevated walkways to help reclaim the street. With one of the highest densities in the world, pedestrians rely heavily on the extremely efficient public transportation system, increasing the number of pedestrians on the street. The need for elevated pedestrian walkways is directly related to pedestrian infrastructure and maintaining a functional public space above the street level. Upper levels prevalent to Hong Kong's development act as a face-lift rejuvenating the ground layer. Central, Hong Kong presents pedestrian movement in a multi-dimensional fashion, pushing the spatial envelope. The elevated walkways portray the city in a new light, helping one escape and step 
above the ever-present chaos. A transformation began in 1997 reshaping Central from the "Asian financial [district] into a retail wonderland" [6]. Catering to pedestrian movement, Aedas' Design further developed Central's elevated system linking together Hong Kong Land properties, Hong Kong's largest landlord, into an interconnected pedestrian web. Together, elevated pedestrian routes allow retail on multiple levels to function successfully adapting the city centre as a pedestrian haven. While North America addresses many of the same sustainable indicators as Hong Kong, the multi-level pedestrian networks continue to fail, leaving the streets decayed. This leads one to ask, what sustainable conditions benefit from elevated pedestrian walkways in Hong Kong?

\section{Pedestrian movement}

Central thrives as a business district during the week, fully utilizing the elevated walkways with not only commuters, but also tourists. Although the flow of movement is stronger during business hours, a continuous flow remains throughout the day. Pedestrian movement at any level links the city into a viable network of patterns connecting each island and space together [7]. In Hong Kong, a permeable network of linked spaces promotes connectivity and convenience, interlinking streets and buildings as a complete pedestrian infrastructure. Hong Kong's elevated network has adopted essential access points making it easy to enter and exit the pedestrian walkways. "Linking is simply the glue to the city. It is the act by which we unite all the layers of activity..." [8] This provides an experience for pedestrians often difficult to find in any North American city. Connectivity and consistency are typically destroyed in the US, blocking potential links with buildings, leaving broken urban conditions. This 'American style' environment prohibits sustainable development.

A longstanding characteristic of Hong Kong's spatial form is layering. Layers added on top of layers are interwoven together to accommodate activities, justified by the way they involve people [9]. The layering system works efficiently in Hong Kong as a result of an interconnected spatial network linking the urban fabric together. The elevated walkways plug into upper levels designed for pedestrian movement, and link carefully into the street and underground. This multi-dimensional network redefines how pedestrians impact and utilize the city. Multiple layers allow public activity to exist at various heights, no longer restricted within the ground level, thus radically improving urban development. This added convenience helps maintain the level of sustainability. However, the primary goal is connecting pedestrians from one consumer activity to the next; privately owed elevated walkways do not allow spontaneous change or events.

\subsection{Public versus private}

Charlotte and Dallas, both Southern US cities residing in warmer climates, are attracted to the modern image of elevated walkways emphasizing a prosperous 
second level. However, sustainably these systems fail, creating an economic dichotomy. Connecting professional offices, luxury hotels, and high-end living spaces integrates a community of high to moderate-income people. Low-income people feel unwelcome or perhaps economically bound, intended or not, placing different classes on separate levels. This pedestrian infrastructure results unintentionally as an internally private sector. Private space interlinks on multiple levels expanding into the public realm; there is no longer a defined line.

Similar issues have surfaced in Hong Kong. Public space in Central, correctly labelled 'ambiguous space', has created a social struggle [10]. Property and legal rights, both public and private, have become a social phenomenon. Private landlords restrict needed development and proper pedestrian connectivity. The results are random unclear links, connecting their private property. However, many of the links are in fact public and fill a gap, providing much needed public space. These spaces are easily recognizable on Sundays occupied with Filipinas relaxing and socializing: "Whether privately or publicly built, skyway networks are a public transportation system" [11]. Architects need to take a stance and address the social separation as well as the bureaucracies that govern over the air rights. They need to lead this development unifying a structured network instead of landowners, lawyers and developers who randomly add additional pieces to the larger unplanned puzzle. It is a struggle within each city as a constant negotiation defining the public spectrum. Elevated walkways function as public spaces residing within the private realm on the second level. Ignoring this social struggle is a professional lack of proficiency, preventing elevated walkways from becoming fully sustainable.

Lisa Law believes gatherings by large groups of Filipina women, currently seen every Sunday, plays a huge role in the success of the publicly owned elevated walkways around IFC, Central [12]. These spaces have adapted to the needs of pedestrians, functioning as a lively vibrant environment 7 days a week. In the mid 70s, women from Mainland China, who typically worked as domestic helpers, were pursuing other jobs. In 1975, 1000 Filipina woman filled this gap [12]. By 1998, close to 150,000 Filipinas worked in Hong Kong as domestic helpers. With limited private space of their own, crowds quickly began to gather publicly on Charter Road, closed for pedestrians in effort to revive downtown. This small effort led to the social phenomenon known today in Hong Kong as 'Little Manila' [12]. Every Sunday and most holidays, the public elevated walkways transform into stomping grounds for local Filipina woman to sprawl out on cardboard box mats, and have a picnic with their friends on their one day off per week. The elevated network in Hong Kong was forced into a social harmony. The primary function of the public walkways switched from fast forward movement amongst the financial business district to a linear gathering space for stopping and socializing. As space is limited, both publicly and privately, odd spaces become an extension of our living comfort zone. Despite the traditional role of a walkway system, the ever-present lack of public space in Hong Kong has redistributed human activity, sustainably adapting the public walkways into awkward public resting spaces. 


\subsection{Continuous flow}

The elevated walkways in Central facilitate a high level of permeability [13]. Pedestrian networks link buildings together, enabling islands to connect as a unified whole no longer isolated [14]. Cutting through the built structure, walkways re-emerge to aid the succession of movement through the space. Spanning several kilometres, each bends and moves in and around the built environment distracting the focus of distance, and replacing it with attention on connectivity. The elevated networks maintain a continuous flow of pedestrian movement throughout the day and night. It functions as a unique urban phenomenon, allowing pedestrians to move freely without vehicular congestion and interruptions from traffic lights. However, comprehensive organization has taken a back seat, due primarily to a monopoly of land ownership. The current system has leaped ahead of itself loosing its full potential. Connections are made to link properties with the same owner, instead of ultimately creating a sustainable comprehensive network linking together the most direct routes to maintain pedestrian flow. In order for this network to be fully sustainable, each link should be positioned to optimize pedestrian movement, so that the entire network is highly attractive [15].

\subsection{Ground floor decay}

Enclosed elevated walkways are quickly becoming a common fixture in more than 80 US cities, separating pedestrians from vehicular traffic. "In a 1991 survey of the 119 North American cities with metropolitan population greater than $150,000,82 \%$ of those responding recorded the existence of some kind of grade-separating pedestrian linkages in their CBD" [16]. Cities such as St. Paul, Cincinnati, Spokane, Charlotte, Indianapolis, Des Moines and Dallas are radically altering their city form. Cincinnati began building elevated walkways in 1970, with the largest density as of 1980, building 17 bridges. With 27 elevated walkways connecting the downtown core of St. Paul, 90\% of the business exists on the second level, leaving the street level as a forgotten wasteland [11]. "Can skywalk systems in places like Minneapolis and Calgary offer lessons for architects?" [5]. Perhaps a better question remains, are skyway systems actually sustainable or perhaps only decaying the street? In Minneapolis, "pedestrians can avoid city streets altogether by using the skywalks" [17]. The addition of elevated walkways has shown a steady decrease of pedestrian activity at the street level. Kent Robertson asks a key question, "Is the economic growth attracted to skywalk development truly growth, or is it redistribution at the expense of the street level activities?" [18]. This avant-garde notion has reinvented pedestrian movement in North American cities. It is a radical idea, extreme from traditional planning.

Central, Hong Kong employs a different strategy. Unlike previous American examples, which left the street level as forgotten territory, Hong Kong placed prime luxury stores, such as Prada, Louis Vuitton, Armani, and Hermes, as a hub on each street level corner attracting shoppers. Not only is the second level a 
prosperous shopping haven at your fingertips; it is also directly connected back into the street. Central simultaneously revamped itself adding pedestrian connectivity in conjunction with a multi-million dollar renovation, as a complete spatial makeover. Maintaining a thriving ground floor is yet another primary difference in the success of Hong Kong's elevated network as a sustainable system. Linking the downtown core into a prosperous pedestrian mecca internally focused within the second floor has led to abandoned streets in the US. Buildings are spaced greater distances apart using elevated walkways to reconnect them. City centres are becoming less and less walkable and more isolated. Elevated walkways are not a solution to urban sprawl. In order to attract people back downtown there must be a balanced intervention.

\section{Quality of life}

It is important to consider the quality of life downtown, creating a balanced vision, a place that people want to live and move within. In the US however, suburbia attracted people away from downtown proposing a better quality of life. Both safety and comfort appealed to many Americans, leaving the downtown core as an empty skeleton. Today, a large percentage of the US population resides within suburbia. Without a proper public transportation infrastructure, too much emphasis is placed on private transportation. As long as this continues, people will drive themselves unless something better is developed. As this phenomenon slowly reverses itself, and people begin to move back downtown, the goal must be to create an ideal quality of life within the heart of the city. This success is directly related to the social and economic development. If consumers are offered an attractive invitation, and urban form is interlinked to facilitate pedestrian movement connecting retail, residential and business, pedestrians will make the extra effort to not only park their cars, but also relocate back downtown. Decayed city centres are labelled as unsafe, dirty and noisy, diverting people to move away. Life in cities takes place when the speed of movement is reduced. This demands space, and preferably enough freedom to move without being pushed or bumped. There is a direct link between quality space and quality of life [19]. Elevated walkways directly address issues of safety, separating pedestrians and vehicular traffic. They also provide a quality of comfort, uniting pedestrian movement as a convenient mode of transportation interconnecting human activity and the built fabric. In order to become fully environmentally sustainable, pedestrian networks need to maintain a spatial standard interconnecting the built environment as a good urban intervention, well linked together.

\subsection{High density}

Hong Kong maintains a unique composition. In contrast to vast North American landscapes, copious to urban sprawl, this densely packed urban form naturally responds to the surreal landscape creating a multi-dimensional urban fabric. With 6.7 million people, and a total land area of $1,100 \mathrm{~km}$, the overall density is 
about 6,100 persons $/ \mathrm{km}$ [20]. High density in Hong Kong enhances movement within the city. Together with a key pedestrian infrastructure, it adds a level of convenience and structure. "Density without a doubt is the most important aspect of urban design, for without sufficient density, a city or an urban area will find it difficult to survive" [9]. A high-density ratio in Hong Kong in conjunction with an efficient public transportation network, secures a percentage of people throughout the city. If one half of this formula fails, it is difficult to sustain an elevated pedestrian network. Density wed with an efficient infrastructure is one of the many dimensions that separate Hong Kong from most North American cities. However, density is sometimes unequally distributed. Streets and walkways become too overcrowded and unable to flourish successfully. Elevated walkways help relieve this pressure allowing for a more sustainable balanced environment. Displacing pedestrian movement to several levels allows for a multi-dimensional idea of the street through re-distribution. Without an elevated pedestrian network, high density could hinder sustainability, allowing overcrowded streets. The elevated walkway system initiates a direct multi-level response to maintain the street level. While this encumbers most North American streets creating ground floor decay, it is a necessity to the success of Hong Kong's urban fabric.

\subsection{Temperature control}

While the primary function of elevated networks in Minneapolis and Calgary, as previously noted, is a direct response to extreme cold climates. Several warmer cities also prefer climate controlled elevated walkways. A series of case studies done by Kent Robertson in five cities (Cincinnati, Des Moines, Duluth, Minneapolis, and St. Paul) interviewing 100 people in each city, concluded that elevated walkways were most often chosen over street-level establishments by $66 \%$ [18]. Also, concluded in the same study, an overall result of $98 \%$ preferred to use elevated walkways on cold weather days. Surprisingly, temperatures of 50 degrees Fahrenheit also averaged $81 \%$ and temperatures of 80 degree Fahrenheit averaged $71 \%$ preferring elevated walkways to sidewalks. From this study, we can conclude that people prefer to move about in a more comfortable climate controlled spatial environment.

Hong Kong on the other hand, has adapted to extreme hot and humid climates. The elevated pedestrian routes provide a continuous breeze that relieves extreme temperatures, and distances pedestrians from vehicular pollution. Pedestrians move freely within a shaded cool open-air zone. A study by Gruen documented that pedestrians would walk 5,000 feet for 20 minutes in a highly attractive, completely weather protected, climate-controlled area, compared to the 600 feet for only 2 minutes in an unattractive environment [21]. Whether relieving extreme cold climates, maintaining a controlled temperature, or allowing breezes to sweep through as a cooling method, attention to temperature is a key sustainable indicator for the success of elevated pedestrian walkways creating a better quality of life. 


\section{Conclusion}

High density, connectivity, and quality of life are three primary elements in maintaining a sustainable elevated walkway system. Together this is a complete package on a social, economic, and environmental level. Undoubtedly, high density is a key ingredient in the success of elevated walkways systems in Hong Kong. In North America, low-density ratios hinder elevated pedestrian movement preventing comprehensive sustainability both socially and economically. Connectivity at multiple levels within a city centre unites buildings together, integrating all aspects of urban form. Elevated pedestrian walkways are a quick link within a greater network to transfer pedestrians from point A to B. However, potentially these walkways could be utilized far more. We need to create resting places, stopping places and breathing spaces within the urban chaos, thus organizing a strong sustainable pedestrian infrastructure. While Hong Kong's elevated system is much more sustainable than those referred to in North America, it does lack in some dimensions. What is missing that would allow all types of movement to fully utilize the walkway networks as a much-needed public space? Perhaps stacking multiple activities is one solution, but why stop there? We can further develop design strategies to provide several activities within the same space at various times of the day [9]. As we begin to redesign cities, we need to focus on creating public spaces that connect and interact with the surroundings, creating a quality of life that attracts people with multiple functions. Providing convenient spaces where people can move quickly to their destination is crucial. If elevated walkways are to become fully sustainable, it is important to consider how multiple functions can exist within the network. We also need to consider how existing buildings could become a part of an intricate pedestrian pattern of prosperous activity. What is to stop cities from further development implementing elevated walkways hundreds of meters above the ground level? It is key to look closely at how elevated walkways can implement the future of urban design. Otherwise it is the architect's act of incompetence disregarding such an urban phenomenon. Perhaps early visions of a 3-D city will become a reality, enriching urban design of the future. More and more cities are developing far too rapidly for their own good. Jane Jacobs defined four principles that make a great street. Perhaps urban designers should rethink modern a "street ballet" [22]. Potentially, elevated walkways can benefit the future of pedestrian movement above the ground layer without killing the street, if used sustainably.

\section{Acknowledgement}

Supervision under J. Karakiewicz, Ph. D., The University of Hong Kong.

\section{References}

[1] Karakiewicz, J., Exploring the Dimensions of Urban Density, Royal Melbourne Institute of Technology, Unpublished Dissertation, Melbourne, 2002. 
[2] Wood, A., Pavements in the sky: the sky bridge in tall buildings, arq, 7 (3/4), 325-332, 2003.

[3] Cook, P., Archigram, Basel: Birkhauser Verlag, ed. 1991.

[4] Alexander, C., The city is not a tree, Design, 206, 46-55.

[5] James, V. \& Yoos, J., The 3-D City, Architecture, 93 (5), 33-35, 2004.

[6] Editorial Staff, Hong Kong Central makeover, Architecture China, 6-12, Autumn 2005.

[7] Cullen, G., Townscape, London, Architectural Press, 1971.

[8] Maki, F., Investigation in Collective Form, no 2 special publication, St. Louis: Washington University, 1964.

[9] Karakiewicz, J., Sustainable High-density environments, The Sustainable City III, WIT Press, 2004.

[10] Cuthbert, A.R. \& McKinnell, K.G., Ambiguous space, ambiguous rights corporate power \& social control in Hong Kong, Cities, 14 (5), 295-311, 1997.

[11] Morphew, C., The ins \& outs of skyways, APA, 50 (3), 23-26, 1984.

[12] Law, L., Defying Disappearance: cosmopolitan public spaces in Hong Kong, Urban Studies, 39 (9), 1625-1645,2002.

[13] Chan, Coway K.H., Pedestrian planning in Central District, A place to work, a place to walk, unpublished dissertation, The University of Hong Kong, 1998.

[14] Trancik, R., Finding Lost Space, New York: Van Nostrand Reinhold, 1986.

[15] Gehl, J., Life Between Buildings, Skive: Arkitektens Forlag, 1996.

[16] Maitland, B., Hidden cities, the irresistible rise of North American interior city, Cities, 9 (3) 162- 169, Aug 1992.

[17] Setter, A., Geography, Breathing Cities: The Architecture of Movement, London: Birkhauser, 2000.

[18] Robertson, K., Pedestrianization strategies for downtown planners, skywalks versus pedestrian malls, APA, 59 (3), 361-370, 1993.

[19] Crookston, M., Clark, P., Averly, J., The Compact City \& The Quality of Life, Compact Cities \& Sustainability, London: E\& FN Spon, 134-142, 1996.

[20] Fung, Bosco C.K., Planning for High Density Development in Hong Kong, Director of Planning, Planning Department, Government of Hong Kong Special Services Administration Region.

[21] Gruen, V., The Heart of our Cities, The Urban Crisis: Diagnostic Cure, New York: Simon \& Schuster, 1964.

[22] Jacobs, J., The Death \& Life of Great American Cities, New York: Random House, 1989. 